Revista Complutense de Historia de América

ISSN: $1132-8312$

http://dx.doi.org/10.5209/RCHA.64693

\title{
Ilegitimidad en Nueva Galicia. El caso de Aguascalientes, siglos XVII y XVIII ${ }^{1}$
}

\author{
Víctor M. González Esparza²
}

Recibido: 6 de junio de 2018 / Aceptado: 8 de abril de 2019

Resumen. Tradicionalmente se ha asociado a la ilegitimidad con el mestizaje en la Nueva España; los estudios específicos se han realizado con bases de datos insuficientes de tal manera que han reafirmado un prejuicio que se observa desde la época colonial. El presente trabajo parte de una base de datos de 200 años para analizar el caso de la ilegitimidad en la parroquia de Aguascalientes y, en este sentido, observar el tema en el largo plazo y en términos comparativos. Los resultados muestran con matices las variaciones de la ilegitimidad en las diferentes "calidades" y, en términos historiográficos, la necesidad de ampliar las bases de datos para la historia serial y comparada.

Palabras clave: Ilegitimidad; mestizaje; Nueva Galicia; Aguascalientes; Siglos XVII-XVIII.

\section{[en] Illegitimacy in Nueva Galicia. The case of Aguascalientes, 17th and 18th centuries}

\begin{abstract}
Illegitimacy has traditionally been associated with miscegenation in New Spain. Specific studies carried out using insufficient databases, have therefore reaffirmed a bias that has been observed since the colonial period. The present study is grounded on data that spans 200 years, so as to analyse the case of illegitimacy within the Aguascalientes parish in the long-term and comparatively. The results reveal nuances in the variations of legitimacy in the different "qualities" and, in historiographical terms, the need to expand databases for serial and comparative history.
\end{abstract}

Keywords: Illegitimacy; Miscegenation; Nueva Galicia; Aguascalientes; 17-18th Centuries.

Sumario. 1. Introducción. 2. La fabricación de un estigma. 3. La ilegitimidad en Aguascalientes, Nueva Galicia. 4. La Carta ampliada de ilegitimidad. 5. Sobre la ilegitimidad europea. 6. Reflexiones finales. 7. Referencias bibliográficas.

Cómo citar: González Esparza, V. M. (2019) Ilegitimidad en Nueva Galicia. El caso de Aguascalientes, ss. XVII y XVIII, en Revista Complutense de Historia de América 45, 211-237.

\footnotetext{
El presente trabajo forma parte de un proyecto más amplio sobre "Resignificar el mestizaje. Tierra adentro".

2 Universidad Autónoma de Aguascalientes (México)

E-mail:vgonzalez@correo.uaa.mx
} 


\section{Introducción}

En el tema de la ilegitimidad, como el de la estructura familiar, pareciera que el futuro está en el pasado. Más allá de las historias lineales y de los modelos, el pasado novohispano de "ilegitimidad y concubinato", pareciera ser el presente de las sociedades desarrolladas, aunque en diferentes términos. Lo que en la actualidad observamos como una de las formas de relacionarse entre las parejas, en donde las uniones consensuadas y el tener hijos fuera del matrimonio alcanzan los más altos niveles históricos por la ampliación de los derechos ${ }^{3}$, para la época colonial es un tema que ha ocupado a los historiadores del "antiguo régimen" demográfico y generalmente se ha observado para Iberoamérica a partir de su relación con el mestizaje.

El concepto de mestizaje ha transitado del prejuicio frente a lo mezclado, a ser parte de la construcción de la identidad mexicana y latinoamericana, para finalmente ser cuestionado por sus contenidos raciales y de ocultamiento de las diferencias sociales $^{4}$. De ahí que, como lo comentara Gruzinsky, la historia de mestizaje presenta varios desafíos, tanto por el uso en términos absolutos y esencialistas de las categorías de "cultura" e "identidad" para describir el proceso, como por las dificultades para comprender el mundo complejo, vago, cambiante del mestizaje a partir de los tradicionales binomios etnocentristas ${ }^{5}$.

Si bien el concepto mismo de mestizaje es una creación del siglo XIX y fue reelaborado por la posrevolución mexicana en términos ideológicos -a partir de la supuesta unión de españoles e indias ${ }^{6}$-, no habría que olvidar que durante la época colonial lo mestizo, dentro de un código de honor basado en la "limpieza de sangre", significó para las élites criollas lo impuro, lo ilegítimo, y para el mundo ilustrado lo degenerado; de ahí que para el México independiente se reivindicara el mestizaje como un proceso de abolición de las castas y del estigma de la piel quebrada. Dada la reciente crítica al concepto del mestizaje, resulta necesario recordar que históricamente se le ha asociado al mestizaje con la ilegitimidad, e incluso la historiografía contemporánea ha repetido lo que parece más un prejuicio, de tal manera que al "patrón mestizo" de la época colonial se le ha igualado con la bastardía?.

3 Coontz, 2006: 357. El matrimonio y la cohabitación no se distinguen ya en Suecia, además de que los hijos fuera del matrimonio pueden ser herederos.

4 Para una crítica al uso del concepto de raza y de mestizaje puede verse el ensayo de Viqueira, 2010. También puede verse con provecho el programa llevado a cabo con motivo de las celebraciones del Centenario "Discutamos México 2010" dedicado al mestizaje: "Mestizaje y diversidad" coordinado por Enrique Florescano, con la participación de Mauricio Tenorio, José Antonio Aguilar Rivera y Juan Pedro Viqueira; disponible en: https:// youtu.be/aZ8JFs3mj2k?list=PLTCv8PKgAsfEEmH_21NhmZ4BpjJY16o5q. Un texto que reflexiona sobre el racismo involucrado en el mestizaje es: Navarrete, 2004: 7-20; el autor planteó la necesidad de un nuevo mapa más allá de mestizos e indios. Su libro más reciente: Navarrete, 2016: 117, comenta sobre la "leyenda del mestizaje" lo que me parece acertado si lo pensamos sólo a partir de la ideología de la mezcla entre españoles e indias; reconoce también la necesidad de mayores estudios para la época colonial, pero el concepto de "confluencia" para entender el proceso a partir del siglo XIX no me parece acertado. Uno de los primeros críticos a la idea del mestizaje fue: Stavenhagen, 1981: 15-84, particularmente sus "Siete tesis equivocadas sobre América Latina".

5 Gruzinski, 2000: 13-63, especialmente los primeros dos capítulos. Los binomios tradicionales pueden ser civilización/barbarie, limpieza/contaminación, legitimidad/ilegitimidad entre muchos otros. En esta misma línea puede verse Alberro, 1992, que muestra el proceso de transformación de uno de los grupos centrales del proceso de mezcla, frente a la idea tradicional y estática de la historia.

6 Zermeño-Padilla, 2008.

7 McCaa, 1991: 582-583. En ella, el autor, además de argumentar que la endogamia era la regla fundamental para formar una pareja, menciona que el "patrón demográfico entre los mestizos se caracterizó también por una 
En un recuento de los temas relacionados con la familia y la vida privada, Pilar Gonzalbo recomendó hace más de veinticinco años revisar esta relación: "Se impone la necesidad, comentó, de revisar el criterio que asimilaba ambas categorías -ilegitimidad y mestizaje- en la historia colonial de México [...]”, por una sencilla razón, de que "no todos los mestizos fueron ilegítimos ni todos los ilegítimos mestizos". Esta asociación entre mestizaje e ilegitimidad en particular requiere nuevos estudios y perspectivas. En ocasiones la ilegitimidad se ha presentado en la historiografía como argumento de la flexibilidad de la sociedad novohispana, sin embargo, el reconocimiento de la diversidad no necesariamente explica la ilegitimidad.

No obstante esta recomendación, la asimilación entre ilegitimidad y mestizaje se ha mantenido en buena medida porque siguen siendo escasos los estudios más concretos al respecto 9 . En un buen balance historiográfico sobre el mestizaje en la América hispánica, un historiador colombiano afirmó: "Está constatado que el mestizaje, ya a comienzos del siglo XVII, llegó a significar ilegitimidad"10. Y cita los trabajos de Thomas Calvo para la Guadalajara del siglo XVII, para concluir al respecto: "El tema de la ilegitimidad, en ocasiones temprana, confirmó con asombro un tema intuido y nombrado: la larga y ostensible historia de la ilegitimidad latinoamericana"11.

Pensar que esta relación está constatada y confirmada en la gran diversidad social de Hispanoamérica parece una conclusión precipitada, principalmente porque como mostraré hacen falta estudios más concretos, de historia serial y de largo plazo que permita avanzar en la comprensión del fenómeno y que además permita la comparación. Después del excelente y multicitado estudio de Thomas Calvo, en donde la demografía se combinaba con ejemplos de caso en una narrativa que anticipaba las historias individuales, es ciertamente difícil revisar ese viejo criterio que ha conectado ilegitimidad y mestizaje especialmente para la Nueva España ${ }^{12}$. Sin embargo, como el propio Calvo lo sugiriera, hacían falta más estudios que dieran cuenta de la diversidad del tema. Manuel Miño Grijalva, como en otros temas, realizó una excelente síntesis al respecto al considerar que la ilegitimidad tuvo comportamientos diferenciados entre los grupos sociales, que disminuyó conforme la Iglesia y el Estado tuvieron más control sobre la familia, que fue una válvula de escape, y que en todo caso la ilegitimidad no fue característica sólo del mundo novohispano ${ }^{13}$. Temas que es necesario recuperar para ayudar a la comprensión de la ilegitimidad.

proporción notable de hijos naturales y abandonados [...]", aunque los porcentajes que ofrece para Parral entre 1770-1794 son sólo de $15 \%$ de hijos naturales y $7 \%$ de hijos de padres desconocidos.

8 Gonzalbo, 1994, cita en p. 153. En esta referencia la autora ponderaba ya ciertas cifras, además de citar el caso de altos porcentajes de ilegitimidad en Guadalajara estudiado por Thomas Calvo, ofrecía también cifras más moderadas para el caso por ejemplo de la ciudad de México. Gonzalbo, 2013; sobre la ilegitimidad, muestra para diferentes años (1730 y 1790) el decrecimiento de la ilegitimidad en dos parroquias de la ciudad de México, si bien reconoce las incongruencias de los registros por calidades. Ibídem: 91-99.

9 Algunas excepciones son: Twinam, 2009, cuyo trabajo supone un esfuerzo por mostrar los contextos complejos de la búsqueda de la legitimidad y del blanqueamiento. Asimismo, Wade, 2009, es una buena síntesis de los principales debates a partir de los temas de género, sexo y mestizaje.

10 Rodríguez Jiménez, 2008.

11 Ibídem: 304.

12 Calvo, 1984 y 1991a. Calvo vino a proporcionar información cuantitativa a un viejo prejuicio. Quien lo llegó a reiterar en sus excelentes libros de síntesis sobre el mestizaje fue: Mörner, 1969 y 1974.

13 Miño Grijalva, 2001: 103-118. Para lo cual cita a Peter Laslett y recordarnos que en el antiguo régimen europeo existía una "subsociedad tendiente a la bastardía". 
Después de los estudios pioneros sobre demografía histórica para el caso novohispano ${ }^{14}$, poco se continuó en general con los temas planteados sobre el mestizaje, especialmente sobre matrimonios mixtos e ilegitimidad, quizá por el seguimiento de modas o por la crítica precipitada a los registros parroquiales por incompletos. Afortunadamente, en los últimos años vivimos una recuperación de la historia de la población, en buena medida por la accesibilidad de las fuentes y la intensión de una comprensión más amplia de la demografía, por lo que es posible revisar los viejos temas con nuevas preguntas.

En este sentido, el objetivo de este ensayo sobre Aguascalientes en la Nueva Galicia, el cual forma parte de un estudio más amplio sobre la resignificación del mestizaje ${ }^{15}$, es analizar el tema de la ilegitimidad en el largo plazo, siglos XVII y XVIII, con el fin de observar los cambios y las características diferenciadas del proceso $^{16}$. También es un esfuerzo por integrar los estudios que se han realizado al respecto, tanto del discurso como de la historiografía, con el fin de tener una visión de conjunto de lo avanzado y de los caminos a seguir. Las fuentes utilizadas en este ensayo son los archivos parroquiales, particularmente de bautizos por calidad durante prácticamente dos siglos en la parroquia de Aguascalientes ${ }^{17}$, con el fin de utilizar las ventajas de la historia serial en el sentido de realizar análisis de largo plazo que nos permitan encontrar la representatividad de un fenómeno. Dada la relevancia de la fuente, con información continua prácticamente para los dos siglos, he integrado una base de datos que comprende también los registros de matrimonio y defunciones a partir del método agregativo en demografía. La reconstitución de familias para algunas regiones de Nueva España ha sido realizada por otros autores, que han mostrado sus posibilidades y sus ventajas ${ }^{18}$. Sin embargo, he optado por el método agregativo a partir de las preguntas que me he hecho sobre el mestizaje, por lo que más que demografía histórica he procurado transitar a la historia de la población replanteando algunas preguntas. Como veremos, existen pocos estudios con estas características, por lo que mi propuesta es avanzar en los estudios comparativos al respecto. Las fechas extremas del estudio son 1602-1800, con más de 300 mil casos entre bautizos, matrimonios y defunciones, por lo que el cierre en el año de 1800 tiene que ver más por razones de cierre dada la cantidad de información, con la idea de continuar posteriormente en el siglo XIX.

14 Para un primer balance de estos estudios, véase: Rabell Romero, 1990. Los trabajos de: Castillo Palma, 2000: 107-137; 2008: 311-427, son una muestra de la nueva demografía, no obstante, permanece la idea de asociar ilegitimidad y mestizaje, si bien reconoce que para el siglo XVIII en Cholula la incidencia de ilegitimidad disminuyó.

15 González Esparza, 2018.

16 Paz, 1998. En "Los hijos de la Malinche" el autor comenta que el rechazo a la Malinche, la madre violada, tiene que ver con el rechazo a nuestra historia, de ahí la conciencia de nuestra soledad [...].

17 Gracias a la digitalización que ha realizado Family Search de los archivos parroquiales, el acceso a estas fuentes permite la renovación de los estudios de historia demográfica. Agradezco en este sentido el apoyo de Enrique Jiménez por la recopilación de la información y a Alfonso Quezada por enseñarme el uso de tablas dinámicas, como parte de un proyecto de investigación sobre el mestizaje en Aguascalientes, en la Universidad Autónoma de Aguascalientes. Gracias a ellos he podido construir una base de datos amplia -que comprende villas y pueblos- para lo que luego se conformaría en un estado de la República.

18 Carbajal López, 2008, 2009 y 2014; Cramaussel, 2014; Torres, 2017. 


\section{La fabricación de un estigma}

Se ha documentado cómo el patriotismo criollo comenzó por reivindicar la tierra y la población americanas a partir de la teoría hipocrática de los humores y temperamentos -coléricos, flemáticos, sanguíneos y melancólicos. Sin embargo, no hay temperamento para los resultados de la mezcla. La disputa de Enrico Martínez y Diego de Cisneros para el caso específico de la Nueva España, si bien se refiere especialmente a los indios americanos y, en sentido amplio, a los nacidos en estas tierras, no tiene una consideración para los mestizos. El primero le otorgaría una complexión "flemática y sanguínea" a los indios, lo cual parecería una combinación favorable. Sin embargo, De Cisneros aclararía que no existe tal combinación: "que el hombre flemático se haga sanguíneo no lo he leído ni oído", y que en todo caso desde Aristóteles sabemos que los flemáticos "para ninguna cosa eran buenos", dado que los de este temperamento flemático son perezosos, olvidadizos, insensatos...Para De Cisneros los indios americanos, dado su buen ingenio y memoria, son de naturaleza melancólica, es decir más bien tristes y sensibles ${ }^{19}$. Quizá la melancolía, como lo argumentara Bartra, sería el temperamento que presagiaría el individualismo de la modernidad y, en este sentido, representaría a la población que era la novedad, aunque la polémica por los temperamentos en la Nueva España habla de una ausencia. Si los españoles eran coléricos y los indios melancólicos, ciertamente la pregunta mayor era sobre el mestizaje: "¿qué ocurre con los temperamentos al producirse la mezcla?" 20 La respuesta no se encuentra, por lo que ante este vacío y sobre todo la ampliación de la población mestiza, se fabricó un estigma ante lo mezclado, que pasa ciertamente por la erotización del otro al pensarlo como ilegítimo, y con ello sujeto de dominación. De ahí la asimilación de mezcla e ilegitimidad.

Para los primeros años de la conquista y de la colonización, ante la escasez de mujeres españolas, ciertamente la ilegitimidad de los primeros mestizos fue mayoritaria no obstante las recomendaciones a los encomenderos, por ejemplo, de casarse con el fin de cumplir con las leyes de la Iglesia y así legitimar a sus herederos. Sin embargo, ante la multiplicación de los mestizos, muy pronto comenzaron a predominar los criterios de jerarquía y dominio. Ciertamente el prejuicio discriminatorio sería más explícito en contra de la negritud y la esclavitud ${ }^{21}$. Sin embargo, si analizamos el prejuicio sobre el mismo concepto de mestizo veremos los matices en los discursos sobre la mezcla social.

En términos de la normatividad, como bien lo comentara Konetzke desde los inicios de la investigación sobre el mestizaje ${ }^{22}$, la política indiana no promovió la unión entre diferentes grupos sociales. No obstante, la Iglesia reconoció la "libre" elección

\footnotetext{
López Beltrán, 2008: 313-326. Puede verse también con provecho: Tappan Velázquez, 2011: 218.

López Beltrán, 2008: 322.

21 Camba Ludlow, 2008. La amplia historiografía sobre la "tercera raíz" en la Nueva España constituye una de las críticas más importantes a la idea tradicional del mestizaje entre españoles e indias: Aguirre Beltrán, 1998. La invitación a este tipo de historias viene también por el lado de la antropología estadounidense: Mintz - Price, 2012. Para el caso mexicano la bibliografía es cada vez más abundante, una síntesis puede consultarse en el libro de Vinson III - Vaughn, 2004, si bien este tipo de introducciones al tema por historiadores estadounidenses han sido criticadas, con razón, por los escasos trabajos citados de estudiosos mexicanos. Véase en esta línea: Velázquez, 2010. Quizá un trabajo complementario en este sentido es el de la misma Velázquez - Iturralde Nieto, 2012. Asimismo, un libro clave para el estudio de las mujeres afrodescendientes y sus representaciones: Velázquez, 2006. Para una historiografía reciente De la Serna, 2013.

22 Konetzke, 1946.
} 
de la pareja con el fin de ampliar la evangelización y los matrimonios, y así limitar los amancebamientos. En la práctica, predominó la aceptación de la elección de las parejas promovida por la Iglesia desde por lo menos el Concilio de Trento ${ }^{23}$. La existencia misma de los registros de los matrimonios mixtos sugiere la importancia del reconocimiento eclesiástico frente a las diferencias de calidad.

La primera generación de mestizos novohispanos se formó a partir de la conquista, con gran escasez de mujeres españolas por lo que, como lo dijera Magnus Mörner, en cierto sentido se trató de una conquista de mujeres ${ }^{24}$. La mayor parte de los españoles en los primeros años tuvieron concubinas e hijos mestizos, algunos de los cuales serían elogiados en el proceso de la guerra de colonización. Los cercanos al grupo materno, por el contrario, y conforme se incrementaba su número, tendrían un lugar indefinido ante la política de separación entre españoles e indios. Ya desde mediados del siglo XVI se conoce el temor del virrey Luis de Velasco por el crecimiento de los mestizos: "Los mestizos van en gran aumento y todos salen tan mal inclinados y tan osados para todas maldades que a estos y a los negros se ha de temer $[\ldots]^{\prime 25}$.

Después de la "invención" del otro en el proceso de conquista, la gran novedad para la historia moderna fueron los mestizos, más allá del primer encuentro de españoles e indias. La llegada de negros esclavos y su participación en las interacciones sociales, de "catalizadores" en el proceso de mezcla ${ }^{26}$, permitió que pronto el mestizo representara no sólo a los hijos de españoles sino también de afrodescendientes e indias. De tal manera que las castas, es decir "mestizos, negros, mulatos y otras castas" como se les nombraba, llegaron a constituir la novedad para fines del siglo XVI y por lo tanto sin un claro referente y ubicación en la sociedad novohispana. De ahí que lo relevante es observar los cambios en el discurso, como lo ha comentado López Beltrán; observar "el traslado de la mirada desde la diferencia moral -hoy diríamos, cultural- a la diferencia física, y el afincamiento en ella de categorías y valoraciones" 27 . Sin embargo, este traslado de la mirada que fue racializando el discurso para el siglo XVIII, partió de un estigma de origen al asimilar mestizaje e ilegitimidad.

La legitimidad de los hijos estuvo vinculada estrechamente al tema de la "limpieza de sangre" y del honor, al "orgullo del linaje" y en términos de género al papel de la mujer en el mantenimiento del orden social. El código colonial del honor orientado a la élite española estuvo basado fundamentalmente en la vigilancia de la sexualidad femenina ${ }^{28}$. Porque el honor implicaba a la pareja, pero sobre todo se centraba en la virginidad femenina, a fin de evitar hijos fuera del matrimonio o ilegítimos, que no tendrían las ventajas de pertenecer a una familia o linaje patriarcal,

23 Seed, 1991. La autora realiza una excelente comparación con la familia "tradicional" europea, sobre todo en el tema de la libertad de elección.

24 Mörner, 1969: 33.

25 Virrey Luis de Velasco, el primero, a Felipe II, México, 7-II-1554, Archivo General de Indias, México, N. 13. Disponible en: http://pares.mcu.es/ParesBusquedas/servlets/Control_servlet?accion=4\&txt_accion_ origen=2\&txt_id_desc_ud=360405; ref. en: Gonzalbo, 2013: 51 .

26 La idea de que los grupos de "afromestizos" fueron el elemento "catalizador" para la mezcla social dada su propensión a contraer matrimonios con otros grupos, es decir a su heterogamia, lo analizo para doscientos años de matrimonios mixtos en otro ensayo: González Esparza, 2018.

27 López Beltrán, 2008: 290.

28 Twinam, 1991. La autora documenta casos en que era posible legitimar lo ilegítimo, lo cual mostraría excepciones sobre el código prevaleciente. 
y que llevaría a las madres a una deshonra pública. El honor por lo tanto se centró en los comportamientos femeninos, en el control estricto de su sexualidad, dado que tener hijos fuera del matrimonio no estigmatizaba a los hombres; más aún, el honor era el mecanismo a través del cual se reproducía la discriminación y la jerarquía de la élite, así como el ideal de la familia patriarcal.

Sin embargo, la sexualidad femenina en la práctica, como bien lo demostrara Twinam, estaba más allá de las dicotomías "virgen soltera o esposa casta, por un lado, y las deshonestas madre soltera y esposa promiscua, por el otro" 29 . Tanto el análisis de los matrimonios mixtos como sobre la ilegitimidad muestran las diferentes implicaciones de este código de honor en las prácticas sociales de las diferentes calidades, incluso en la época de mayor recrudecimiento de este tipo de políticas, por ejemplo, a partir de la Pragmática de $1776-78^{30}$. Si este código de honor tuvo dificultades en instrumentarse ampliamente entre la élite, mayor fue la diferencia entre prácticas y representaciones entre las castas. De ahí que la política de la corona si bien mostró contradicciones y ambigüedades, por ejemplo, entre las disposiciones civiles y las establecidas por la Iglesia, también tuvo criterios para las diferentes calidades con el fin de mantener la jerarquía y la distinción, el monopolio de la riqueza y de los privilegios.

Un caso paradigmático en el discurso colonial es el de Solórzano Pereira, quien en su Política Indiana, sin duda un reconocimiento a la defensa del indio por el Imperio así como una defensa de la legitimidad de los criollos, presenta la visión sobre el mestizaje en general -en los que incluye a los mulatos y otras castas-al reafirmar la idea sobre la mancha que estigmatizó "la mixtura de sangre".

Según este autor, los mestizos "lo más ordinario es que nacen del adulterio, o de otros ilícitos y punibles ayuntamientos [...] sobre él cae la mancha del color vario y otros vicios, que suelen ser como naturales y mamados en la leche [...]" Considera además que deben pagar tributo los mestizos en general, como ya lo han establecido algunas cédulas, ya que "no debe ser más privilegiada la lujuria que la castidad $[\ldots]^{’ 31}$. Esta visión de una de las mentes más esclarecidas e influyentes ante Felipe III advierte del discurso imperante, frente a una realidad que rebasaba los criterios tradicionales de percibir el mundo ${ }^{32}$. Porque la reiteración de que se les cobrara tributos deja ver la opinión prevaleciente de incorporarlos al sistema tributario para no privilegiar más "la lujuria que la castidad", porque bajo esta idea los mestizos debían pagar tributos más que los indios dada su mancha original. Ello mostrará confusión y ambigüedad ante la dificultad de reconocer a los otros, pero sobre todo al distinguir a la "plebe" infame y degenerada de las buenas familias.

No deja de sorprender el informe de Sigüenza y Góngora sobre los participantes en el "alboroto y motín" de 1692, en donde la plebe "tan en extremo plebe" se amotina en contra de la falta de alimentos:

29 Ibídem: 132-133.

30 Twinam, 2001.

31 Solórzano Pereira, 1648: 244-248. Curiosamente la lectura de Mörner sobre Solórzano Pereira es más bien positiva sobre los mestizos: Mörner, 1969: 51, nota 32. Esta idea sobre los vicios de los mestizos se encuentra también en el informe de los hermanos Ulloa sobre el Perú: Ulloa, y Ulloa, 1826: 399. Sobre la conveniencia de poblar en tierras de indios con mestizos, los Ulloa comentaron: "se reducen a que siendo gente inquieta, holgazana y viciosa estos mestizos que se desterrasen a los gobiernos, sería de temer en ellos alguna sublevación [...]"; además recomendaban mandar con ellos mujeres para evitar mayores dificultades. Ciertamente es menor el comentario de los Ulloa sobre mestizos que sobre los vicios de curas...

32 Un análisis de esta idea de Solórzano Pereira la encontramos en: Stolcke, 1992: 204. 
porque, siendo plebe tan en extremo plebe, que sólo ella la puede ser de la que se reputare la más infame, y lo es de todas las plebes, por componerse de indios, de negros, criollos y bozales de diferentes naciones, de chinos, mulatos, de moriscos, de mestizos, de zambaigos, de lobos y también de españoles que, en declarándose zaramullos -que es lo mismo que pícaros, chulos y arrebatacapas-y degenerando de sus obligaciones, son los peores entre tan ruin canalla $[\ldots]^{33}$.

El prejuicio sobre el mestizaje también fue reelaborado por el "protonacionalismo criollo", es decir, por la defensa criolla ante la disputa por el nuevo mundo en el siglo XVIII, particularmente ante la idea ilustrada de la degeneración de las razas. Tenemos otro testimonio de un virrey a principios del siglo XVIII. Se trata de Fernando de Alencastre Noroña y Silva, duque de Linares, Marqués de Valdefuentes, Porta Alegre y Govea, trigésimo quinto Virrey de la Nueva España (1711-1716), a quien cito sobre la sociedad novohispana:

se compone de diferentes castas que han procreado los enlaces de español, indio y negro; pero confundiendo de tal suerte su primer origen, que ya no hay voces para explicar y distinguir estas clases de gentes que hacen el mayor número de habitantes del reino. Degenerando siempre en sus alianzas, son correspondientes sus inclinaciones viciosas, miran con entrañable aborrecimiento la casta noble del español y con aversión y menosprecio la del indio $[\ldots]^{34}$.

El contexto de la disputa por el nuevo mundo nos advirtió de los prejuicios ilustrados sobre el mestizaje. Sin embargo, poco conocemos las estrategias de los pensadores criollos para distinguirse de los mestizos frente a los criterios españoles. De ahí que la polémica de Eguiara y Eguren contra el deán de Alicante, Manuel Martí, sobre la supuesta falta de tradición intelectual "mexicana", exprese esta diferenciación. Juan José Eguiara y Eguren, rector de la Universidad Pontificia, era el más influyente pensador de su tiempo y respondería al deán valenciano con el puntual registro que llevara acabo de la tradición intelectual y cultural tanto prehispánica como mexicana, además de ser el integrador de la idea del mestizaje a partir de las uniones entre españoles e indígenas para fundamentar el nacionalismo criollo ${ }^{35}$.

Andrés Arce y Miranda, colaborador para la "Biblioteca mexicana" de Eguiara y Eguren, escribió confidencialmente sus opiniones sobre las mezclas sociales ${ }^{36}$. En sus notas, llamadas "Noticias de los escritores de la Nueva España", comentó que las escribía "para sacar en limpio la pureza de sangre de los criollos literatos; pues se debe recelar de la preocupación en que en la Europa están de que todos somos mezclados -o como decimos champurros-, influyó no poco en el olvido en que tienen los trabajos de los beneméritos". Cuestionaría incluso el nombre mismo de "criollo",

33 Sigüenza y Góngora, 1984.

34 Villarroel, 1999: 194. El informe del virrey Linares es de 1720, poco después de su encargo para pintar una serie de castas. Para un análisis amplio del rechazo al mestizaje, véase: López Beltrán, 2008.

35 Eguiara y Eguren, 1986-1990. Existen varios trabajos que han tratado la "polémica mexicana" con Martí: De la Torre Villar, 1993: 133-150; Comes Peña, 2003; Rovira, 1993-1994.

36 Castro Morales, 1983. Arce y Miranda era amigo de Eguiara y Eguren y formaba parte del círculo intelectual alrededor del rector de la Universidad Pontificia; había sido educado con los jesuitas, hasta obtener su doctorado en teología, para después ocupar unos curatos y ser nombrado obispo de Puerto Rico, cargo al que renunció. Lamentablemente el autor no menciona dónde se encuentra el texto de Arce y Miranda. 
porque "sobre ridículo es denigrativo e infamativo" dado que fue inventado para los hijos de los esclavos negros en América ${ }^{37}$. La idea de rescatar el pasado de la pureza de sangre era también una forma de diferenciarse de los "champurros", de ahí la reproducción de un prejuicio que estigmatizaría a la mezcla social al presentarla como "ilícita". De esta manera el desprecio a la gente de piel quebrada, incluidos algunos mestizos, estuvo alimentado por las pugnas entre peninsulares y criollos, ya que ambos grupos exageraron su orgullo racial. De acuerdo con Guillermo Céspedes, los peninsulares "enrostraban a los criollos sus gotas de sangre mestiza y en consecuencia exageraron unos y otros su orgullo racial de blancos en el correlativo desprecio por la gente de color" 38 .

\section{La ilegitimidad en Aguascalientes, Nueva Galicia}

Más allá de los discursos, es necesario el regreso a las fuentes. En este caso parroquiales de Aguascalientes, una subregión de Nueva Galicia, Tierra Adentro, para los siglos XVII y XVIII. El matizar de acuerdo a las diferentes calidades y a los tiempos puede contribuir a comprender el tema, más allá del discurso asociado entre mestizaje e ilegitimidad.

El caso de Aguascalientes puede ser representativo dado que se encuentra ubicado en una zona central entre Zacatecas y Guanajuato, en la transición entre el Bajío y las tierras semidesérticas del norte de la Nueva España, en un espacio en donde una nueva sociedad se conformó a partir de la dinámica global que caracterizó a la "Norteamérica española" y que fue estructurada por el Camino real de Tierra Adentro ${ }^{39}$. La hipótesis ofrecida por John Tutino en el sentido de que la dinámica del capitalismo tuvo en la región del Bajío hasta Zacatecas y más allá un centro y no una periferia, junto con la integración de una población diferenciada por sus amplias mezclas de calidades y su espíritu de trabajo, plantea nuevas interrogantes y posibilidades de investigación. En este sentido es que podemos insertar este estudio sobre las características de la población en dicha región caracterizada por un gran dinamismo, sobre todo a partir de la segunda mitad del siglo XVII.

Aguascalientes fue Alcaldía mayor de la Nueva Galicia y Subdelegación de la Intendencia de Guadalajara, y uno de los principales centros ganaderos de la región desde sus orígenes caracterizado por grandes latifundios ${ }^{40}$. En el siglo XVII fue zona de frontera dado lo tardío del poblamiento, a partir sobre todo del cambio de estrategia de la guerra a "fuego y sangre" hacia la necesidad de poblar los grandes territorios obtenidos. Después de una primera mitad del siglo incierta, la crisis del s. XVII se expresaría sobre todo en los años treinta, para tener una clara expansión a partir de la segunda mitad de este siglo hasta alcanzar una población de poco más de siete mil habitantes a fines del mismo. El crecimiento de la población sería sobre todo en el siglo XVIII, ya que la Subdelegación alcanzaría una población de más de 25 mil

37 Ibídem: 671-690, quien analiza el texto de Arce y Miranda. Para una incorporación también del texto de Arce y Miranda, ver: Katzew, 2004: 94. También comenta la autora que fue idea original del virrey Linares presentar al rey de España y a la Corte las diferentes mezclas raciales mediante los cuadros de Juan Rodríguez Juárez.

38 Mörner, 1969: 62.

39 Tutino, 2016.

40 Serrera, 1977. Existe una versión reciente (2016) editada por la Universidad Autónoma de Aguascalientes y El Colegio de San Luis. 
habitantes, a un ritmo de crecimiento de más del 4\% anual no obstante las grandes crisis de mortalidad. La población de Aguascalientes, a diferencia de los centros mineros, de las grandes ciudades y las costas, estuvo dividida de manera tripartita entre españoles, indios y castas hasta bien entrado el siglo XVIII ${ }^{41}$.

La parroquia de Aguascalientes en términos territoriales para el siglo XVII, con base en el Padrón de 1648, comprendía 50 casas en la villa, el pueblo de San Marcos, 4 haciendas y 18 casas en los alrededores. De acuerdo a esta misma fuente, vivían en la Parroquia 991 personas, de los cuales 76 eran niños y 5 sin categoría, de confesión y/o comunión ${ }^{42}$. El Padrón muestra ya una conformación diversa, la siguiente tabla (Tabla 1) nos ofrece una perspectiva en este sentido, en donde se muestra un elemento central poco considerado, los altos porcentajes de la población de castas:

Tabla 1. Padrón de Aguascalientes, $1648^{43}$.

\begin{tabular}{|l|c|c|c|}
\hline & Hombres & Mujeres & Total \\
\hline Indios & 186 & 184 & 370 \\
\hline Españoles & 125 & 143 & 268 \\
\hline Castas & & & \\
\hline Negros esclavos & 13 & 23 & \\
\hline Negros libres & 6 & 9 & \\
\hline Negros sc & 55 & 39 & \\
\hline Mulatos esclavos & 16 & 22 & \\
\hline Mulatos libres & 22 & 20 & \\
\hline Mulatos sc & 12 & 7 & \\
\hline Mestizos & 16 & 12 & \\
\hline Castas & 140 & 132 & 272 \\
\hline & & & \\
\hline Suma & 451 & 459 & 910 \\
\hline & & & \\
\hline Niños & 59 & 17 & \\
\hline Otros & 3 & 2 & \\
\hline Total & & & \\
\hline
\end{tabular}

$41 \quad$ Para mayor profundidad en las características de la población, véase: González Esparza, 2018.

42 Gutiérrez Gutiérrez, 1999. El autor, además de ofrecer una breve introducción, paleografió y transcribió generosamente todo el Padrón.

43 Fuente: elaboración propia a partir de Gutiérrez Gutiérrez, 1999. 
Gráfico 1. Padrón de 1648. Población de Aguascalientes (Porcentajes).

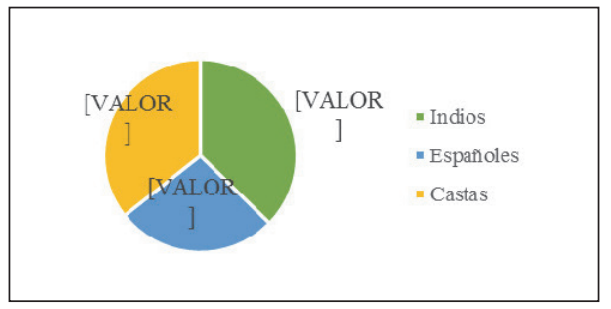

Para el siglo XVIII la población creció a un ritmo acelerado -hasta en un 4 por ciento anual-, de tal manera que la parroquia necesitó de ayudas o nuevos curatos, como fueron para Aguascalientes los casos del real de Asientos (1731), Pueblo Nuevo/San José de Gracia (1769, posteriormente Rincón de Romos), y finalmente Valle de Huejúcar/ Calvillo (1771). La información presentada aquí incluye para el siglo XVII los datos de la parroquia original de Aguascalientes, y para el siglo XVIII los demás curatos ${ }^{44}$.

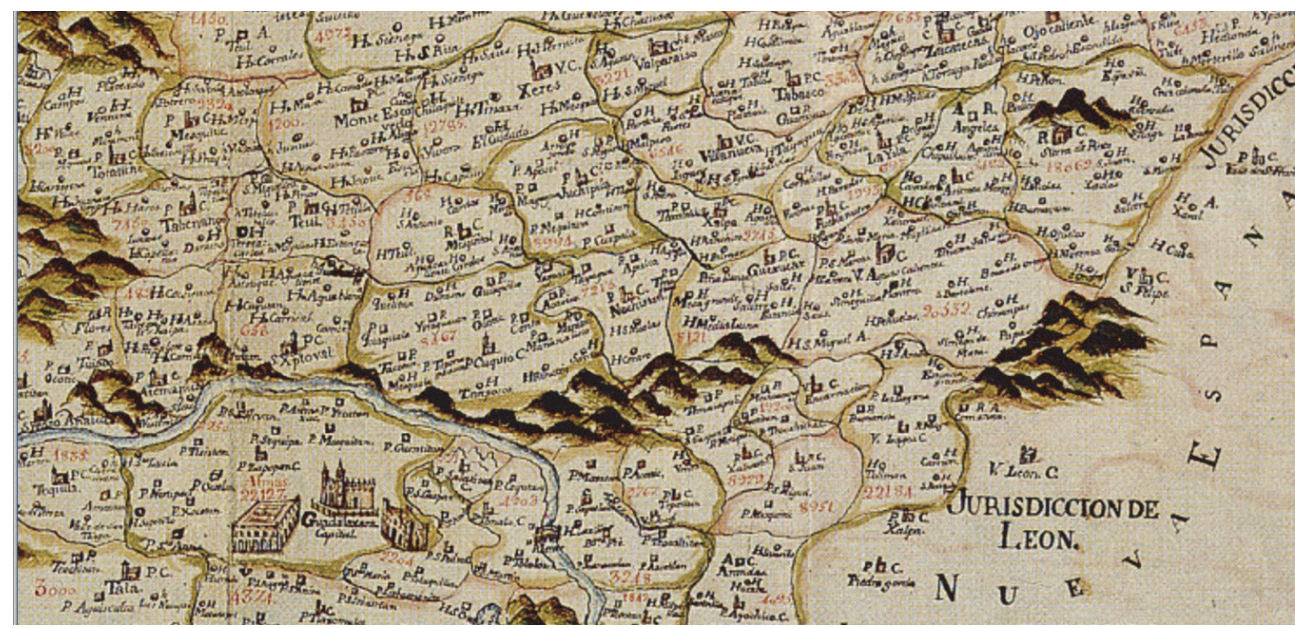

Figura 1. Recuadro del "Plano de los curatos del reino de Nueva Galicia, 1780"45.

Para el análisis, he integrado las diferentes calidades en tres: Indios, Españoles y Castas, comprendiendo estas últimas los diversos grupos que durante la época novohispana permanecieron más bien diferenciados, dada la política de otorgarle justicia a cada individuo que en la práctica era una manera de mantener separadas a las diferentes castas por el riesgo de los motines y rebeliones.

44 Cabe señalar que los curatos de Monte Grande o San José de la Isla y de Villa de Gutiérrez del Águila (Villanueva) formaron parte de la Parroquia de Aguascalientes en 1770 -según lo reportó el Doctor Mateo Joseph de Arteaga-, sin embargo, poco después pasarían a la jurisdicción de Zacatecas. Así ocurrió al menos con otros casos como el de Encarnación de Díaz y la ayuda de parroquia de Ciénega de Mata, que pasarían a la jurisdicción de Guadalajara.

45 Realizado por Anastacio Ponce por orden del oidor Eusebio Sánchez Pareja (1780). Archivo General de Indias, M-P México 360. Disponible en: http://pares.mcu.es/ParesBusquedas/servlets/Control_servlet?accion=4\&txt accion_origen=2\&txt_id_desc_ud=21230. En él, aparecen Zacatecas al norte en la derecha, Aguascalientes al centro hacia la derecha y Guadalajara al sur a la izquierda. 
Así pues, para el caso de Aguascalientes en 1648 vemos un alto porcentaje de indios $(37,3 \%)$ y de castas $(36,6 \%)$, con el 27,1 por ciento para españoles, lo cual nos habla de un proceso de colonización hacia Tierra Adentro en donde la población indo-afromestiza jugó un papel más relevante que lo tradicionalmente reconocido. Para el siglo XVIII se mantuvo prácticamente la composición tripartita, con un incremento sobre todo entre la población española, de acuerdo al Censo General de la Intendencia de $1791-93^{46}$ (Tabla 2).

Tabla 2. Distinción de Calidades, Intendencia de Guadalajara y Subdelegación de Aguascalientes (1791-1793) ${ }^{47}$.

\begin{tabular}{|l|c|c|c|c|}
\hline \multicolumn{1}{|c|}{ Calidades } & Intendencia & $\mathbf{\%}$ & Subdelegación & $\mathbf{\%}$ \\
\hline Españoles y Europeos & 99.454 & 31,7 & 10.046 & 39 \\
\hline Indios & 113.426 & 36,2 & 8.617 & 33,5 \\
\hline Mulatos y Otras Castas & 100.492 & 32,1 & 7.095 & 27,5 \\
\hline Total & 313.372 & 100 & 25.758 & 100 \\
\hline
\end{tabular}

Ahora bien, para analizar el tema de la ilegitimidad un primer acercamiento a través de lo gráfico para los dos siglos puede ofrecer un panorama global, diferenciando calidad y legitimidad (Gráfico 2). En términos generales, resalta el grado de legitimidad para los dos siglos, no así la ilegitimidad. De tal manera que no corresponde a la tradicional idea de que la ilegitimidad era una característica de la sociedad novohispana.

Gráfico 2. Bautizos por calidad y legitimidad, Aguascalientes ss. XVII y XVIII ${ }^{48}$.

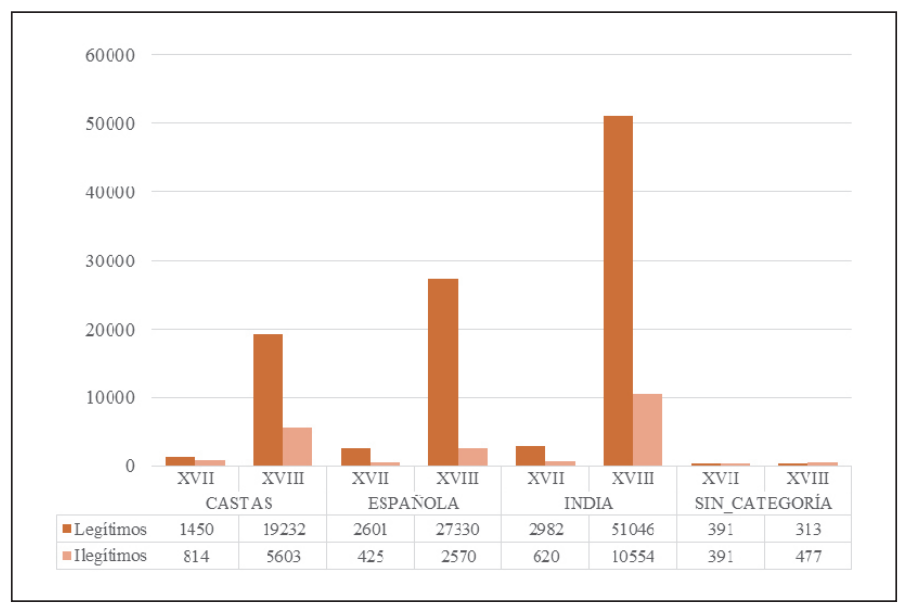

46 González Esparza, 2018.

47 Fuente: Menéndez Valdés, 1980: 111 y 153; Castañeda - Gómez, 2000, especialmente el cuadro 7 de la p. 60; Commons, 1995.

48 Fuente: Elaboración propia a partir de: Family Search, 1612-1800. 
De manera más precisa, como se observa en las siguientes Tablas (Tabla 3 y 4), la comparación en el tiempo nos advierte también de un modelo de transición que va de un porcentaje general en los registros de ilegitimidad del 23,3 por ciento en el siglo XVII, al 16,4 en el siglo XVIII. El punto que también es relevante es que entre las castas es en donde la ilegitimidad es mayor, 36 por ciento para el s. XVII, y 22.6 para el s. XVIII, aunque también en una tendencia claramente a la baja.

En el siglo XVII el porcentaje de ilegitimidad entre españoles e indios es 14 y 17,2 por ciento respectivamente. Ahora bien, si lo analizamos con base en el número de ilegítimos con respecto al total de bautizos, la proporción cambia. Por ejemplo, del total de los bautizos registrados para el siglo XVII, 9.674 casos, sólo 814 fueron de ilegítimos para castas -es decir el 8,4 por ciento, 12,4 si incluimos incluso los registros sin calidad-y así con respecto a las demás calidades: 6,4 por ciento para población india y 4.4 para española.

Tabla 3. Ilegitimidad/Legitimidad por calidad, Aguascalientes, siglo XVII ${ }^{49}$.

\begin{tabular}{|l|c|c|c|c|c|c|c|}
\hline Calidad & Ilegítimos & $\begin{array}{c}\text { \% } \\
\text { Bautizos } \\
\text { por calidad }\end{array}$ & $\begin{array}{c}\text { \% Bautizos } \\
\text { ilegítimos/ } \\
\text { Total general }\end{array}$ & Legítimos & $\begin{array}{c}\text { \% Bautizos } \\
\text { por calidad }\end{array}$ & $\begin{array}{c}\text { \% Bautizos } \\
\text { legítimos/ } \\
\text { Total general }\end{array}$ & Total \\
\hline India & 620 & 17,2 & 6,4 & 2.982 & 82,8 & 30,8 & $\mathbf{3 . 6 0 2}$ \\
\hline Española & 425 & 14 & 4,4 & 2.601 & 86 & 26,8 & $\mathbf{3 . 0 2 6}$ \\
\hline Castas & 814 & 35,9 & 8,4 & 1.450 & 64 & 14,9 & $\mathbf{2 . 2 6 4}$ \\
\hline Sin Categoría & 391 & 50 & 4 & 391 & 50 & 4 & $\mathbf{7 8 2}$ \\
\hline Total & $\mathbf{2 . 2 5 0}$ & $\mathbf{2 3 , 2}$ & $\mathbf{2 3 , 2}$ & $\mathbf{7 . 4 2 4}$ & $\mathbf{7 6 , 7}$ & $\mathbf{7 6 , 7}$ & $\mathbf{9 . 6 7 4}$ \\
\hline
\end{tabular}

Para el siglo XVIII el porcentaje de ilegitimidad en general disminuyó en comparación al siglo anterior -del $23,3 \%$ al $16,4 \%-$, particularmente entre las castas -del $36 \%$ al 22,6\%- lo cual de alguna manera representa paradójicamente el triunfo de las políticas sociales tanto del clero como de la corona. Ante la insistencia de la poca capacidad infraestructural del poder de la corona, a través de esta información para la región de Aguascalientes, vemos el avance de las políticas integradoras e incluso ecuménicas, al mismo tiempo que de control de la población, al disminuir las tasas de ilegitimidad y en ese sentido incrementar el número de los matrimonios.

El porcentaje de ilegitimidad de españoles también disminuye, aunque en menor proporción -del 14\% al 8,6\%-, y el porcentaje de registros de ilegítimos entre indígenas se mantuvo en el mismo nivel -del 17,2 al 17,1\%-que en el siglo anterior. Sin embargo, en relación al total de bautizos el porcentaje de bautizos ilegítimos de la población indígena se incrementó de un siglo a otro -del 6,4 al 9 por ciento-, al incrementarse en general el número de bautizos de esta calidad. En términos generales, más del 50 por ciento de los bautizos fueron entre la población considera india. La pregunta que surge nuevamente es porqué el notable crecimiento de los registros de bautizos, tanto de legítimos como de ilegítimos entre la población india, en

49 Fuente: Elaboración propia a partir de: Family Search, 1612-1800. 
proporción a las otras calidades. Una hipótesis de trabajo para posteriores estudios es que existió una política de incrementar la base tributaria, por una parte, y por la otra el que la población de otras castas prefiriera ser considerada india por los privilegios que conllevaba esta calidad ${ }^{50}$.

Tabla 4. Ilegitimidad/Legitimidad por calidad, Aguascalientes, siglo XVIII ${ }^{51}$.

\begin{tabular}{|l|c|c|c|c|c|c|c|}
\hline Calidad & Ilegítimos & $\begin{array}{c}\text { \% } \\
\text { Bautizos } \\
\text { por calidad }\end{array}$ & $\begin{array}{c}\text { \% Bautizos } \\
\text { ilegítimos/ } \\
\text { Total general }\end{array}$ & Legítimos & $\begin{array}{c}\text { \% Bautizos } \\
\text { por calidad }\end{array}$ & $\begin{array}{c}\text { \% Bautizos } \\
\text { legítimos/ } \\
\text { Total general }\end{array}$ & Total \\
\hline India & 10.554 & 17,1 & 9 & 51.046 & 82,9 & 43,5 & $\mathbf{6 1 . 6 0 0}$ \\
\hline Española & 2.570 & 8,6 & 2,2 & 27.330 & 91,4 & 23,3 & $\mathbf{2 9 . 9 0 0}$ \\
\hline Castas & 5.603 & 22,6 & 4,8 & 19.232 & 77,4 & 16,4 & $\mathbf{2 4 . 8 3 5}$ \\
\hline Sin Categoría & 477 & 60,4 & 0,4 & 313 & 39,6 & 0,26 & $\mathbf{7 9 0}$ \\
\hline Total & $\mathbf{1 9 . 2 0 4}$ & $\mathbf{1 6 , 4}$ & $\mathbf{1 6 , 4}$ & $\mathbf{9 7 . 9 2 1}$ & $\mathbf{8 3 , 6}$ & $\mathbf{8 3 , 6}$ & $\mathbf{1 1 7 . 1 2 5}$ \\
\hline
\end{tabular}

Así pues, en general los registros sobre ilegitimidad no sólo muestran una clara tendencia a la baja, sino también nos advierten, contrario a la opinión común, que la mayor parte de los bautizos eran de hijos legítimos - del 73 al 84\%-en ambos siglos, lo que pondera algunas cifras parciales sobre la ilegitimidad. Nos muestran también el avance del proyecto borbónico para disciplinar no sólo la vida política, sino también social y familiar, regular el deseo sobre todo entre españoles y las castas. El porcentaje de legitimidad en los registros entre las castas, por ejemplo, se incrementó del 64 por ciento al 77,4, lo cual habla del incremento de los matrimonios en esta calidad no obstante la Ley pragmática de fines del periodo colonial. Por otra parte, el incremento de los registros de ilegitimidad en términos absolutos entre la población india nos habla de una política más consciente de ampliar la base de los tributarios, no obstante, su ilegitimidad.

Analizar series en el largo plazo ofrece una perspectiva que tiene diferentes implicaciones sobre la historia de la familia y permite también descartar algunos estereotipos sobre la sociedad aguascalentense y, por la amplitud del estudio, novohispana. La ilegitimidad fue parte de la construcción de una sociedad compleja y contradictoria, flexible y jerárquica, que permitió una diversidad en la práctica como pocas sociedades, si bien las representaciones sobre todo para el siglo de los borbones eran de un proyecto que pretendió ordenar y disciplinar a partir del cuestionamiento de las mezclas.

50 Sobre las reformas tributarias a partir de la visita de José de Gálvez en los años sesenta del siglo XVIII, con el fin de ampliar la base de la recaudación, véase: Díaz Rementería, 1979; Pollack, 2016. Pollack comenta que, a diferencia de otros sistemas tributarios, el de Hispanoamérica si bien reforzaba la idea de homogeneidad de cada pueblo, "se categorizaba a los tributarios principalmente según su designación socioétnica, edad y estado civil". (p. 89) Las reformas borbónicas fijaron la tasación del tributo en 16 reales para los indios y 24 para las castas. (p. 104). Para un excelente ejemplo de la relevancia del estudio de los tributos, consúltese: Obara-Saeki - Viqueira Alban, 2017.

51 Fuente: Elaboración propia a partir de los Registros parroquiales: Family Search, 1612-1800. 
Los primeros estudios sobre la ilegitimidad, enfocados en pequeños periodos escasamente de una generación, descubrieron las altas tasas de ilegitimidad sobre todo para el siglo XVII y principalmente en ciudades. A partir de ahí, siguiendo incluso algunos prejuicios españoles de la época, se pensó que la ilegitimidad era sinónimo del mestizaje.

Este estudio más amplio en el análisis de los registros pondera y matiza muchas de las afirmaciones sobre la ilegitimidad. Concretamente para el caso de Aguascalientes, un lugar de frontera a fines del siglo XVI y primera mitad del siglo XVII, pero que pronto se consolidaría como una villa comercial relevante en el Camino Real de Tierra Adentro, y con un territorio rural centrado en la ganadería, mostraría un porcentaje de ilegitimidad más cercano a los patrones de villas y ciudades mineras en el norte de la Nueva España. Ahora bien, surgen varias preguntas ¿Qué tan representativo es el caso de Aguasalientes? Se trata de una población socialmente diversificada, incluso distribuida proporcionalmente entre los tres principales grupos sociales o calidades, por lo que puede ayudar a ser más significativos los resultados. También es importante considerar que el caso de Aguascalientes, sobre todo para el siglo XVIII como hemos comentado, se han considerado además de la propia villa de Aguascalientes considerada de españoles, como sería el caso de Calvillo también, dos pueblos de indios - como San José de Gracia y Jesús María-, así como un real de minas -Asientos-, por lo que los resultados pueden ser considerados con mayor grado de representatividad. El siguiente apartado tiene la finalidad de analizar los demás estudios de caso realizados para Nueva España, y algunos más conocidos en general de Hispanoamérica, y de esta manera observar comparativamente los resultados del caso de Aguascalientes ${ }^{52}$.

\section{La Carta ampliada de ilegitimidad}

Ciertamente el estudio de un solo caso no puede generalizar sus resultados. De ahí la importancia de establecer algunos puntos de comparación que permitan una mayor contextualización. Habría que recordar precisamente el discurso clásico de Marc Bloch al respecto, en un momento de resurgimiento de los nacionalismos después de la primera guerra mundial, en donde propuso una historia comparada más allá de la especulación y a partir de comparaciones bien definidas, la cual llamó una historia comparada de "horizontes limitados". Su preocupación central estaba precisamente en posibilitar la comparación a partir de indicadores y "unidades de comparación" que permitieran salir del causalismo local y del provincianismo metodológico $0^{53}$. "La historia comparada, comentó Bloch, con plena libertad para conocer y para servir, animará a su vez a los estudios locales, sin los que ella nada puede hacer pero que tampoco podrían llegar a nada sin ella" ${ }^{4}$. En este sentido, me parece pertinente utilizar el indicador de la ilegitimidad para observar algunas variaciones para el contexto hispanoamericano, y con ello reflexionar más ampliamente al respecto.

Los pioneros trabajos de Thomas Calvo, como se ha comentado, son un referente obligado; Calvo encontró para la Guadalajara del siglo XVII cifras verdaderamente

\footnotetext{
Dubert, 2015. De utilidad es la tabla 1, p. 57, particularmente notable el caso del norte del Portugal.

Bloch, [1928], 1999.

Ibídem: 144-147.
} 
escandalosas, al grado de que se llegó a preguntar si América Latina pertenecía al mundo hispánico y por ende al occidental ${ }^{55}$. El promedio general de nacimientos fuera del matrimonio para dicho siglo en Guadalajara era, de acuerdo a Calvo, 55,4\% del total de los bautizos, y hasta el 60,5\% para mulatos. Sin embargo, para las diferentes calidades el autor sólo analiza 5 años, 1692-93 y 1698-1702. No obstante que se trataba de un primer hallazgo, los siguientes trabajos al respecto observaron una relación estrecha entre mestizaje e ilegitimidad, hasta hacerlos prácticamente sinónimos. Sin embargo, es necesario revisar los datos ${ }^{56}$.

La siguiente tabla (Tabla 5), "Carta ampliada de ilegitimidad mexicana", fue elaborado con base en una propuesta inicial de Ann Twinam y desarrollado por este autor para mostrar algunas diferencias, pero también, pese la diversidad de los casos, algunos patrones que pueden ayudarnos a entender mejor el proceso ${ }^{57}$. La tabla sintetiza, por otra parte, la historiografía sobre la ilegitimidad en la Nueva España.

Tabla 5. Carta ampliada de ilegitimidad hispanoamericana, ss. XVII y XVIII ${ }^{58}$.

\begin{tabular}{|l|c|c|c|c|c|}
\hline \multicolumn{1}{|c|}{ Localidad } & Años & $\begin{array}{c}\text { Españoles } \\
\mathbf{( \% )}\end{array}$ & $\begin{array}{c}\text { Indios } \\
\mathbf{( \% )}\end{array}$ & $\begin{array}{c}\text { Castas } \\
\mathbf{( \% )}\end{array}$ & $\begin{array}{c}\text { Total } \\
\mathbf{( \% )}\end{array}$ \\
\hline Calvo, Thomas_Guadalajara & $1692-1693$ & 39 & 50 & 51,7 & 48,1 \\
& $1698-1702$ & & & 12,6 & \\
\hline Calvo, Thomas_Acatzingo & $1650-1712$ & & 4,1 & & \\
\hline Morin, Claude_Zacatelco & $1720-1802$ & & 4 & & \\
& $1721-26$ & & 2,7 & & \\
\hline Pescador_Ciudad de México (Sagrario) & $1785-91$ & & 34,8 & 37 & 36,4 \\
& 1753 & 27,7 & 31,6 & 32,3 & 31 \\
& 1762 & 17,3 & 31,6 & 29,6 & 27 \\
& 1782 & 23,7 & 32,6 & 44,3 & 36,2 \\
\hline Gonzalbo_Cd. México-Santa Veracruz, & 1730 & 34,1 & 26,3 & 30,5 & 30,1 \\
Sagrario & & 36 & 33,3 & 47,1 & 38,7 \\
Gonzalbo_Santa Veracruz, & 1790 & 18,7 & 9,9 & 18,9 & 15,8 \\
Sagrario & & 18,3 & 26,8 & 24,5 & 23,2 \\
\hline Chena, Rodolfo_Chilapa & $1772-82$ & & & & 11 \\
\hline
\end{tabular}

55 Calvo, 1989, 1991a, 1992 y 1984; Alberro, 1991.

56 Un primer estudio sobre la ilegitimidad se lo debemos a Borah - Cook, 1966. Aunque se refieren a información sobre todo del siglo XX, presenta promedios de nacimientos ilegítimos para los años 1900-05 y 1959-61 para cada estado de la república, y consideran el tema de la ilegitimidad como una cuestión "cultural" heredada por lo menos desde el periodo colonial. No obstante, como otros trabajos de estos pioneros, su comparación entre mexicanos y México-americanos es muy sugerente.

57 Twinam, 2001.

58 Fuente: He elaborado esta tabla con el fin de establecer criterios comparativos, de ahí el que he integrado la información en sólo tres calidades. El punto de partida fue el trabajo de Twinam, 2001: 222. Para el caso de Guadalajara retomé las cifras proporcionadas por Calvo, 1991, cuadro XI; Gonzalbo, 2013: 93-95, cuadros 1518. Pueden consultarse además los estudios de Carmagnani, 1972; Castillo Palma, 2008: 348; González Flores, 2016. Para el caso de Argentina: Ghirardi, 2004: 408-411. Para el caso del Nuevo Reino de Granada los datos fueron tomado de: Dueñas Vargas, 1995: 209. 


\begin{tabular}{|c|c|c|c|c|c|}
\hline Localidad & Años & $\begin{array}{c}\text { Españoles } \\
(\%)\end{array}$ & $\begin{array}{c}\text { Indios } \\
(\%)\end{array}$ & $\begin{array}{c}\text { Castas } \\
(\%)\end{array}$ & $\begin{array}{l}\text { Total } \\
(\%)\end{array}$ \\
\hline Castillo Palma_Cholula & $1652-1741$ & 24 & 5 & 20,3 & 25 \\
\hline $\begin{array}{l}\text { Rabell, Cecilia_San Luis de la Paz, } \\
\text { Guanajuato }\end{array}$ & $\begin{array}{c}1645-1664 \\
1700-1719 \\
1750-1769 \\
1790-1809 \\
1645-1809\end{array}$ & $\begin{array}{c}6,8 \\
10,3 \\
10,5\end{array}$ & $\begin{array}{c}43,7 \\
12,6 \\
9,6 \\
5\end{array}$ & $\begin{array}{c}26,3 \\
27,2 \\
13,4 \\
9\end{array}$ & $\begin{array}{c}25,6 \\
14,5 \\
10,5 \\
7,5 \\
14,5\end{array}$ \\
\hline $\begin{array}{l}\text { Carmagnani, Marcelo_Charcas, SLP } \\
\text { Carmagnani, Marcelo_San Luis Potosí }\end{array}$ & $\begin{array}{l}1605-1699 \\
1710-1724 \\
1605-1724 \\
1605-1654\end{array}$ & $\begin{array}{c}15,8 \\
17 \\
16,4 \\
25,6\end{array}$ & $\begin{array}{c}13,8 \\
17 \\
15,4 \\
14,8\end{array}$ & $\begin{array}{c}41,7 \\
31,6 \\
35,6 \\
66\end{array}$ & $\begin{array}{l}23,7 \\
21,8 \\
22,4 \\
35,4\end{array}$ \\
\hline McCaa, Robert_Parral & 1770 & 6 & & 30 & 22 \\
\hline González Flores_Taximaroa, Michoacán & $\begin{array}{l}1667-1700 \\
1701-1826 \\
1667-1826\end{array}$ & $\begin{array}{c}16 \\
8,9 \\
12,4\end{array}$ & $\begin{array}{l}7,3 \\
6,1 \\
6,7\end{array}$ & $\begin{array}{l}29,6 \\
16,9 \\
23,2\end{array}$ & $\begin{array}{l}17,6 \\
10,6 \\
14,1\end{array}$ \\
\hline González Esparza_Aguascalientes & $\begin{array}{l}1616-1700 \\
1701-1800 \\
1616-1800\end{array}$ & $\begin{array}{c}14 \\
8,6 \\
11,3\end{array}$ & $\begin{array}{l}17,2 \\
17,1 \\
17,1\end{array}$ & $\begin{array}{c}36 \\
22,6 \\
29,3\end{array}$ & $\begin{array}{l}22,4 \\
16,1 \\
19,8\end{array}$ \\
\hline Promedio general Nueva España & & 23 & 22.5 & 30.2 & 25.2 \\
\hline \multicolumn{6}{|l|}{ Virreinato Río de la Plata } \\
\hline Arcondo_Córdoba & $1780-1799$ & & & 50 & \\
\hline Celton_Córdoba & $1778-1784$ & 45,1 & & 53,7 & \\
\hline Ferreyra_Córdoba-ciudad & $1760-1790$ & 27 & & 50,9 & \\
\hline Ferreyra_Córdoba-campaña & & 10,8 & & 53,5 & \\
\hline García_Tucumán & $1790-1810$ & 10 & 37 & & \\
\hline Santa Fé & 1767 & & & & 17 \\
\hline Ciudad & $1783-1786$ & & & & 50 \\
\hline Rural & $1776-1785$ & & & & 27,6 \\
\hline Pampa porteña, Luján & $1780-1800$ & & & & 16,5 \\
\hline Pampa porteña, Magdalena & $1738-1765$ & & & & 13,6 \\
\hline \multicolumn{6}{|l|}{ Nuevo Reino de Granada } \\
\hline Dueñas Vargas, Guiomar_Catedral, & $1765-1795$ & 20.3 & 53,5 & 69,7 & 47,8 \\
\hline Dueñas Vargas, Guiomar_Las Nieves, & $1765-1795$ & 39,1 & 55,6 & 58,7 & 51,1 \\
\hline
\end{tabular}

Como podemos observar en la Tabla anterior, los periodos de análisis en la mayoría de los estudios son cortos y fragmentados -el mayor periodo considerado es el de Taximaroa y, como lo desarrollaremos, sobre Aguascalientes-, por lo que me 
parece que se llegaron a conclusiones anticipadamente -caracterizar la sociedad novohispana y en general la Iberoamericana por la ilegitimidad-sin tener los estudios necesarios de largo plazo al respecto.

Los estudios presentados en la Tabla ofrecen una gama amplia que va, en general, del 6 al 66 por ciento de ilegitimidad en los registros de bautizos, quizá en buena medida debido a la inconsistencia de las fuentes consultadas en la mayoría de los casos. Ello también se observa analizando las diferentes calidades: en los indios del 5 al 50 por ciento; entre los españoles del 6 al 39, y entre las castas del 12 al 66 por ciento. Ciertamente el mayor porcentaje lo encontramos en general entre las castas -incluidos mestizos, mulatos y otras-, por lo que estos porcentajes son un indicio de la disposición a la heterogamia, es decir a mezclarse con personas fuera del propio grupo, pero no necesariamente como explicación del mestizaje a partir de la ilegitimidad.

Salvo los casos extremos encontrados por Calvo $(50 \%)$ y Rabell $(47,3 \%)$ en el siglo XVII para la población indígena, los registros de ilegitimidad entre ésta tienden a ser más bajos, con un promedio general $(22,5 \%)$ muy similar al de los españoles $(23 \%)$.

Por otra parte, las variaciones en los indicadores de ilegitimidad también atienden si era en ciudad, en pueblos o en el campo, siendo mayores en promedio los porcentajes en ciudades como Guadalajara (48\%), Ciudad de México (36,4\%) y San Luis Potosí (35,4\%); intermedios en pueblos mineros como Charcas $(23,7 \%)$ y Parral (22\%) o villas como Aguascalientes (19,8\%) productoras de ganado y cereales y relacionadas con la minería, y definitivamente bajos en pueblos mayoritariamente de indios como en Taximaroa, Michoacán (14,1\%), San Luis de la Paz, en el actual estado de Guanajuato (9,6\%), o Chilapa, Guerrero (11\%). Dada las variaciones en el poblamiento entre el centro/sur y las regiones de Tierra Adentro, también se pueden observar diferencias en la ilegitimidad de los bautizos entre el norte y el sur de la Nueva España. El mayor porcentaje de ilegitimidad, pues, está en las ciudades y entre las castas, lo cual nos habla de procesos específicos relacionados con las grandes oleadas migratorias de las que hablara Félix María Calleja hacia fines del siglo $\mathrm{XVIII}^{59}$. El incremento de la legitimidad, por otra parte, también tiene su explicación como veremos en el éxito de las políticas de la corona y de la Iglesia para controlar las uniones libres.

Si analizamos los casos que registran los cambios entre el siglo XVII y XVIII las mayores transformaciones los observamos en las series de más largo plazo, es decir en los casos de Taximaroa y Aguascalientes: de 7 puntos en el primer caso y de 6,6 por ciento en el caso de Aguascalientes. Una tendencia a la baja entre los españoles, pero sobre todo entre las castas, que para el caso de Aguascalientes es de hasta más de 13 puntos porcentuales. Entre los indios prácticamente no hay variaciones en el indicador entre uno y otro siglo, salvo en el caso de San Luis de la Paz.

En todo caso, para las diferentes calidades la tendencia es a la baja entre los datos de un siglo a otro, o incluso dentro del mismo siglo XVIII - no en los datos de Pescador, pero sí en los de Gonzalbo para la ciudad de México-, lo que viene a

59 Calleja, 1792. Calleja conocía bien tanto la región de Puebla como de Colotlán y Aguascalientes, sobre las que había redactado informes para el virrey Revillagigedo. En esta descripción previa al Padrón de Revillagigedo para Aguascalientes, menciona como característica central de la población la migración, dada la escasez de trabajo y de los bajos salarios. 
mostrar las variaciones, pero también una tendencia a la baja que es compartida por los diferentes estudios que permiten la comparación ${ }^{60}$.

Para el caso de Argentina, Mónica Ghirardi ha encontrado, con bases de datos discontinuas, tendencias similares sobre todo en las diferencias entre calidades, entre campo/ciudad y en el tiempo, en una tendencia hacia la baja de la ilegitimidad. La autora también plantea la comparación con Europa, y relaciona las concepciones premaritales lo cual, comenta, "de ser considerado, elevaría los niveles de sexualidad extramatrimonial en las poblaciones europeas", lo cual desarrollaremos más adelante $^{61}$.

Para el caso del Nuevo Reino de Granada, el estudio de Dueñas Vargas continúa siendo el referente principal; con una temporalidad de treinta años (1770-1810) observó altas tasas de ilegitimidad en el nacimiento de prácticamente las tres calidades principales, con un promedio general superior al $50 \%$, en una tendencia hacia el alza particularmente en la parroquia de Las Nieves ${ }^{62}$.

Ahora bien, la explicación de las altas tasas de ilegitimidad se encuentra no en la propensión "natural" de los mestizos o negros y mulatos a la ilegitimidad, al grado de identificar mestizos con vicio y degeneración. Más bien, puede relacionarse a otros fenómenos de la época, particularmente a las constantes y enormes olas migratorias que conformarían intermitentemente a las ciudades, o en zonas de frontera en donde el control de la Iglesia era menor o se había reducido. En este sentido, el papel de la Iglesia y sus sacerdotes era central en el trato a los hijos ilegítimos dentro de una visión ecuménica, y en la posterior transformación cultural que implicó considerar a los hijos ilegítimos como bastardos y a las concubinas como amantes ${ }^{63}$.

Esta transición que se observa a partir de la supresión de los privilegios a unas y otros, pasa necesariamente por el control de la legalidad en el matrimonio y en los nacimientos. Existían otras formas de legitimación posterior, por ejemplo, el presionar a los cónyuges para matrimoniarse, y normalizar así el lugar de sus hijos "naturales"; otra estrategia fue también a través de las "gracias al sacar", es decir del impuesto establecido por la corona con el fin de cambiar el estatus originalmente ilegítimo o de mestizo, mulato, pardo o lobo ${ }^{64}$.

Así pues, lo que muestra este ejercicio comparativo es principalmente que la ilegitimidad mayor se observa en las zonas urbanas o mineras, o bien en las costas, y particularmente entre las castas. Se observa también una tendencia hacia la baja en los estudios de más largo plazo - Taximaroa y Aguascalientes-, y en el siglo XVIII en donde se puede observar un mayor control de las prácticas matrimoniales por parte de la corona y de la Iglesia.

Existe otro punto de comparación con el "modelo europeo" y que tiene algunos matices que es necesario recordar, a partir de la consideración de los embarazos prematrimoniales y sobre todo el registro del matrimonio antes del nacimiento del bebé para evitar la bastardía, lo cual nos lleva a distinguir algunas diferencias más culturales en la explicación de la ilegitimidad.

60 Esta tendencia se puede observar también para el siglo XIX (de 1826-1900) en México, para el caso de Sombrerete estudiado por Arenas Hernández, 2014:137, en donde sólo el 9,9 por ciento eran hijos ilegítimos y expósitos.

61 Ghirardi, 2004: 408-411.

62 Dueñas Vargas, 1995: 209.

63 Mateo, 1996.

64 Twinam, 2015. 


\section{Sobre la ilegitimidad europea}

La comparación explícita con algunas regiones europeas sobre la ilegitimidad en la época moderna puede ayudar a comprender más integralmente nuestros resultados, pero sobre todo reflexionar sobre un tema relevante para entender en particular a la sociedad novohispana. Las diferencias desde luego y los contextos diversos pueden ayudar en este sentido.

En la Europa medieval no sería sino hasta el siglo XV que se profundizarían las normas a favor del matrimonio monogámico, por lo que "del mismo modo que la Iglesia impuso la monogamia perpetua como única forma de matrimonio válida, impuso a los hijos legítimos como únicos herederos auténticos de su padre" ${ }^{65}$. Ello desde luego impulsaría el afán por la legitimidad, además de las políticas en relación al honor y a la limpieza de sangre para el caso español.

Existen desde luego variaciones para el caso europeo, sin embargo, la tendencia a la baja en la ilegitimidad en los siglos XVI y XVII se vería trastocada en los inicios de la revolución industrial y las nuevas formas de trabajo, momento en que se dispararían los registros de ilegitimidad ${ }^{66}$. Por otra parte, como bien lo sugiriera Peter Laslett, habría que considerar el tema de los embarazos premaritales para el caso europeo, lo cual permite una aproximación más adecuada al tema.

Para el caso específico de España en la Edad Moderna, la ilegitimidad será mayor en las ciudades: un 10\% de los bautismos en Granada, en los siglos XVI y XVII, y hasta un $15 \%$ en Madrid eran hijos de padres desconocidos ${ }^{67}$. Por la cercanía con el caso de la Nueva España, los estudios realizados por Isidro Dubert para la sociedad gallega del "antiguo régimen" son un buen referente dada la diversidad del "modelo europeo". Para este autor, los niveles de ilegitimidad experimentaron un "franco y neto despegue" a partir de 1770-1780 en Galicia interior, hasta alcanzar un 17\% para mediados del siglo XIX ${ }^{68}$. Ciertamente durante los siglos XVI a XVIII en general las tasas de ilegitimidad en esta región no alcanzaron el 6\%; sin embargo, junto con las concepciones premaritales las cuales alcanzaron hasta un $12 \%$ de los nacimientos, se puede tener una visión diferente de las tasas en la península ibérica, de tal manera que estaríamos hablando de tasas cercanas al 18 por ciento, y aún mayores en el norte de Portugal ${ }^{69}$.

Por otra parte, como bien lo relacionara Peter Laslett desde sus pioneros trabajos, las altas tasas de embarazos premaritales, sobre todo en Alemania e Inglaterra donde se han realizado más estudios al respecto, nos habla de una mayor capacidad de respuesta inmediata tanto de la familia como de las Iglesias para evitar la bastardía y por lo tanto mantener el derecho a heredar, en otras palabras para mejorar no sólo los indicadores sino también los dramas familiares al resolver el matrimonio antes del nacimiento del primogénito ${ }^{70}$.

\footnotetext{
Otis-Cour, 2000: 62.

66 Goody, 2001. En algunos casos, la ilegitimidad era una estrategia también entre la élite para relacionarse con grupos ascendentes, por ejemplo, entre los mercaderes genoveses en Granada y las mujeres castellanas. Girón Pascual, 2013. Una excelente síntesis al respecto son también los trabajos reunidos en: Kertzer - Barbagli, 2002.

67 Casey, 2001: 65.

68 Dubert, 2015: 49-86.

69 Ibídem, en especial tabla I, 57.

70 Laslett, 1980: 128-133, especialmente cuadro 3.3.
} 
Sobre los siglos XVI y XVII los historiadores ingleses han descubierto que "entre una quinta parte y la mitad de las novias estaban embarazadas al casarse, y más de la mitad en el siglo XVIII. Este era también el caso de Noruega, donde casi la mitad de los primogénitos nacían a los ocho meses de matrimonio" $"$. Para el siglo XVIII, el promedio de hijos nacidos en los ocho primeros meses en Alemania crece del $13,4 \%$ al $21 \%$ después de 1750 ; para el caso inglés pasa del 19,7\% al 35,7 en el mismo periodo ${ }^{72}$. Lo cual representa, si le agregamos las tasas de ilegitimidad, comportamientos similares entre el viejo y el nuevo mundo con diferentes registros. La diferencia se encuentra en las maneras de entender la ceremonia y en la respuesta de las Iglesias; en el caso inglés, "si el embarazo era evidente antes de la boda formal y ambas partes afirmaban que había un acuerdo, se organizaba una boda pública en la iglesia, aunque la novia no llevase la típica corona de boda $[\ldots]^{\text {"73. }}$. Si el embarazo era en mujeres solteras o sin pareja entonces se convertía en un asunto grave.

Para el caso novohispano, dada la fijación de la honra en la virginidad para las mujeres españolas y criollas de la élite, el embarazo se ocultaba al grado de enclaustrar literalmente a la novia hasta el nacimiento del bebé -o hasta su pérdida-, el cual muchas veces no era reconocido por la familia; en el caso de las mujeres indias o de castas se daba el amancebamiento hasta el registro y en su caso formalización del matrimonio, aunque los hijos se registraban como ilegítimos. Así pues, la relativa tolerancia en el caso de la Europa del norte respecto a los embarazos premaritales, a diferencia del mundo iberoamericano en donde un embarazo antes del matrimonio era ocultado como una deshonra, influyó en el registro de la ilegitimidad.

Con el fin de abrir las posibilidades de comprender el proceso de ilegitimidad en Hispanoamérica, Ann Twinam ha llevado a cabo estudios amplios sobre las posibilidades de cambiar el estatus de ilegítimos a través de los casos de "gracias al sacar". Al mismo tiempo no ha advertido de que la sexualidad y el honor particularmente entre las mujeres de la élite era muy diferente al código establecido sobre el honor y la virginidad ${ }^{74}$. Ciertamente lo que este y otros estudios muestran es el grado de flexibilidad en las relaciones, más allá del código español sobre la observancia de ciertos preceptos. No obstante, en términos sociales más amplios, el código sobre el honor que impulsaron sobre todo los borbones recrudeció las contradicciones entre una sociedad flexible frente a discursos excluyentes. La idea de que el ámbito público era diferente al privado nos sugiere además el tema de las apariencias que engañan, propio de la literatura barroca. Pero, ¿las relaciones premaritales, como sugiere Twinam, eran aceptadas al igual que en varias regiones europeas? Ello nos plantea la necesidad de estudios más amplios, por lo que el debate queda abierto.

\footnotetext{
Wiesner-Hanks, 2000: 74.

Flinn, 1989, el promedio que utilizo para después de 1750 está integrado.

Wiesner-Hanks, 2000.

74 Twinam, 2009, comenta que tanto para el caso europeo como el hispanoamericano la tolerancia o aceptación a las relaciones premaritales era en ambos casos generalizada, y que los hijos ilegítimos tenían posibilidad de heredar o ser legitimados posteriormente... Sin embargo, y aquí habría que abogar por más estudios comparativos, sobre la aceptación a las relaciones premaritales en el mundo hispanoamericano la autora comenta que sólo encontró dos referencias, véase nota 21. Este argumento tiene que ver con todo el trabajo de Twinam sobre la posibilidad de que ilegítimos pudieran legitimarse a través de "gracias al sacar". Twinam, 2015.
} 


\section{Reflexiones finales}

Más allá de visones teleológicas y eurocentristas que afortunadamente comienzan a abandonarse, en donde la relación centro/periferia se ha transformado para dar paso a perspectivas más complejas y pluricéntricas, el estudio de una región en el centro norte de la Nueva España, en la llamada "Norteamérica española", puede conectarnos con uno de los centros mundiales de producción de plata -entre Guanajuato y Zacatecas-, que comienza a revelarnos una nueva sociedad con una amplia hibridación y patrones no necesariamente muy alejados de otros centros. Por ello el tema de la ilegitimidad, que tradicionalmente se ha asociado al mestizaje, requiere estudiarse para observar las diferencias con otros modelos. El tema de la ilegitimidad ha estado asociado al mestizaje y en general a la historia latinoamericana; los primeros estudios al respecto insistieron en la ilegitimidad como si se tratara de un patrón excepcional, si bien las bases de datos utilizadas no fueron suficientemente consistentes para concluir prematuramente que se trataba de una estrecha relación entre ilegitimidad y mestizaje. Ello nos llevó a analizar el discurso en la construcción de un estigma, en donde la legitimidad/ilegitimidad era una manera de excluir y dominar.

El estudio de caso de Aguascalientes, Nueva Galicia, en un periodo de cerca de doscientos años nos permite señalar cambios en los patrones de ilegitimidad entre el siglo XVII y XVIII, en una clara tendencia a la baja en los porcentajes particularmente entre las castas. Las diferencias entre las calidades son importantes, dada la tendencia a la baja en la ilegitimidad tanto en españoles como en castas. En términos comparativos, el mayor porcentaje de ilegitimidad se dio en las zonas urbanas, o de frontera como en zonas mineras y en las costas, y entre las castas, lo cual nos habla de patrones de alta migración. Sin embargo, la tendencia en todos los casos que permiten la comparación en el largo plazo, fue hacia la baja, lo cual por otro lado incorpora del papel de la Iglesia y de la corona en general para ampliar las condiciones de legitimidad.

La comparación con el caso europeo muestra ciertamente diferencias, pero sobre todo en la manera de realizar los registros frente a la concepción más estricta de la bastardía -y por lo tanto de matrimonios antes del nacimiento del bebé-, ya que como se ha señalado al menos desde Laslett, la incorporación al análisis de los embarazos prematrimoniales en los casos europeos tiende a igualar los parámetros no de la ilegitimidad sino de las relaciones prematrimoniales. En este sentido la manera de controlar el deseo marca las diferencias, lo cual abre nuevas preguntas.

Finalmente, la historia comparada es cada vez más pertinente para analizar este tipo de procesos, de "horizonte limitado" como los llamara Bloch, en el sentido de que pueden basarse en estudios críticos y sólidamente documentados que permitan comparaciones fructíferas. Por ello la necesidad de contar con bases de datos amplias y de largo plazo, que posibiliten salir de la fragmentación y del regionalismo historiográfico y contribuir así a una comprensión global de la historia social Iberoamericana.

\section{Referencias bibliográficas}

Aguirre Beltrán, Gonzalo. Obra Antropológica II, La Población negra de México. Estudio etnohistórico. México: Fondo de Cultura Económica-Instituto Nacional Indigenista, Universidad Veracruzana, Gobierno de Veracruz, $3^{\text {a }}$ ed. corregida y aumentada, 1998. 
Arenas Hernández, Tomás Dimas. La población de Sombrerete de 1826 a 1900. Dinámica demográfica y minería. México: Instituto Zacatecano de Cultura, 2014.

Bloch, Marc. "A favor de una historia comparada de las civilizaciones europeas" [1928]. En Historia e historiadores, textos reunidos por Bloch, Étienne. Madrid: Ed. Akal, 1999.

Borah, Woodrow y Cook, Sherburne F. "Marriage and Legitimacy in Mexican culture: Mexico and California". California Law review, vol. 54, n 2 (1966), 946-1008.

Calleja, Félix. "Descripción de la Subdelegación de Aguascalientes". En Padrones, vol. 5, coordinado por Calleja, Félix. México: Archivo General de la Nación, 1792, fojas 1-10.

Calvo, Thomas. "Concubinato y Mestizaje en el medio urbano: el caso de Guadalajara en el siglo XVII”. Revista de Indias, vol. XLIV, n 173 (1984), 203-212.

- La Nueva Galicia en los siglos XVI y XVII. México: El Colegio de Jalisco, Centro de Estudios Mexicanos y Centroamericanos, 1989.

— "Calor de hogar: las familias del siglo XVII en Guadalajara". En Sexualidad y matrimonio de la América hispánica, coordinado por Lavrin, Asunción. México: Consejo Nacional para la Cultura y las Artes, Ed. Grijalbo, 1991a, 309-338.

- Poder, religión y Sociedad en la Guadalajara del siglo XVII. México: Centro de Estudios Mexicanos y Centroamericanos, $1991 \mathrm{~b}$.

- Guadalajara y su región en el siglo XVII, Población y Economía. México: Ayuntamiento de Guadalajara, 1992.

Camba Ludlow, Úrsula. Imaginarios ambiguos, realidades contradictorias. Conductas y representaciones de los negros y mulatos novohispanos, Siglos XVI y XVII. México: El Colegio de México, 2008.

Carbajal López, David. La población en Bolaños, 1740-1848. Dinámica demográfica, familia y mestizaje. México: El Colegio de Michoacán, 2008.

— "Reflexiones metodológicas sobre el mestizaje en la Nueva España. Una propuesta a partir de las familias del real de Bolaños, 1740-1822". Letras Históricas, n ${ }^{\circ} 1$ otoño-invierno 2009, 13-38.

- (coord.). Familias pluriétnicas y mestizaje en la Nueva España y el Río de la Plata. México: Universidad de Guadalajara, 2014.

Carmagnani, Marcelo, "Demografía y sociedad: La estructura social de los centros mineros del norte de México, 1600-1720”. Historia Mexicana, vol. XXI, n 3, enero-marzo, 1972: 419-459.

Casey, James. España en la Edad Moderna. Una historia social. España: Universitat de València, 2001.

Castañeda, Carmen - Gómez, Laura G. "La población de Guadalajara de acuerdo con el padrón militar de 1791 y el censo de la intendencia de 1793". Historias, n 45 (2000), 45-65.

Castillo Palma, Norma Angélica. "Matrimonios mixtos y cruce de la barrera de color como vías para el mestizaje de la población negra y mulata". Signos Históricos, vol. 2, n 4 diciembre (2000), 107-137.

- Cholula, Sociedad mestiza en ciudad india. México: Plaza y Valdés, UAM, $2^{\text {a }}$ ed., 2008.

Castro Morales, Efraín. "Los cuadros de castas de la Nueva España". Jahrbuch für Geschichte von Staat, Wirtschaft, und Gesellschaft Latinoamerikas, $\mathrm{n}^{\circ} 20$ (1983), 671-690.

Comes Peña, Claudia. "Diálogos americanos en torno a una polémica: las respuestas a Martí, deán de Alicante". En Diálogos culturales en la Literatura Iberoamericana, Actas del XXXIX Congreso del Instituto Internacional de Literatura Iberoamericana, editado por Reverte Bernal, Concepción. España: Ed. Verbum, 2003, 257-267.

Commons, Áurea. "La Población de Nueva España en 1790". TEMPUS, Revista de Historia de la Facultad de Filosofía y Letras, no 3 (1995), 70-74. 
Coontz, Stephanie. Historia del matrimonio. Cómo el amor conquistó el matrimonio. España: Gedisa editorial, 2006.

Cramaussel, Chantal. "Mestizaje y familias pluriétnicas en la villa de San Felipe El Real de Chihuahua y multiplicación de los mulatos en el septentrión novohispano durante el siglo XVIII”. En Familias pluriétnicas y mestizaje en la Nueva España y el Río de la Plata, coordinado por Carbajal López, David. México: Universidad de Guadalajara, 2014, 17-45.

De la Serna, Juan Manuel, "Esclavizados y libres. Historia e historiografía de México". En Cartografías afrolatinoamericanas: perspectivas situadas para análisis transfronterizos, editado por Guzmán, Florencia - Geler, Lea. Buenos Aires: Ed. Biblos, 2013, 263-273.

De la Torre Villar, Ernesto. "Defensa y elogio de la cultura mexicana". En Juan José de Eguiara y Eguren y la cultura mexicana, coordinado y presentado por De la Torre Villar, Ernesto. México: Universidad Nacional Autónoma de México, 1993, 133-150.

Díaz Rementería, Carlos J. "El régimen jurídico del rramo de tributos en Nueva España y las reformas peruanas de Carlos III". Historia mexicana, vol. 28, n 3 (1979), 401-438.

Dubert, Isidro. "Ilegitimidad, matrimonio y mercados de trabajo femeninos en la Galicia interior, 1570-1899”. Obradoiro de Historia moderna, no 24 (2015), 49-86.

Dueñas Vargas, Guiomar. "Gender, race and Class: Illegitimacy and family life in Santa Fe Nuevo reino de Granada, 1770-1810". Tesis Doctoral, University of Texas at Austin, 1995.

Eguiara y Eguren, Juan José. Bibliotheca mexicana, 5 vols. Compilado, prólogo y notas por De la Torre Villar, Ernesto con la colaboración de Navarro de Anda, Ramiro. México: Universidad Nacional Autónoma de México, 1986-1990.

Family Search. Family history library, Aguascalientes, Bautizos, Matrimonios y Defunciones 1602-1800.

Flinn, Michael W. El sistema demográfico europeo, 1500-1820. España: Editorial Crítica, 1989.

Florescano, Enrique (coord.). "Discutamos México 2010” dedicado al mestizaje: "Mestizaje y diversidad". Con la participación de Tenorio, Mauricio - Aguilar Rivera, José Antonio - Viqueira, Juan Pedro. 2010. Disponible en https://youtu.be/aZ8JFs3mj2k?list=PLTCv8 PKgAsfEEmH_21NhmZ4BpjJY16o5q

Ghirardi, Mónica. Matrimonios y familias en Córdoba, 1700-1850. Prácticas y representaciones. Argentina: Universidad Nacional de Córdoba, Centro de Estudios Avanzado, 2004.

Girón Pascual, Rafael M. "Exogamia, endogamia e ilegitimidad: estrategias familiares de los mercaderes genoveses de Granada durante la edad moderna (ss. XVI-XVIII)". Historia y Genealogía, no 3 (2013), 83-98.

Gonzalbo, Pilar. "Familia y vida privada: dos temas paralelos". Obradoiro de historia moderna, $n^{\circ} 3$ (1994), 147-160.

— "La Trampa de las castas”. En La Sociedad Novohispana. ¿Estereotipos y realidades?, editado por Alberro, Solange - Gonzalbo, Pilar. México: El Colegio de México, 2013, 15-191.

González Esparza, Víctor M. Resignificar el mestizaje Tierra Adentro. Aguascalientes, Nueva Galicia, Siglos XVII y XVII. México: El Colegio de San Luis, Universidad Autónoma de Aguascalientes, 2018.

González Flores, José Gustavo. Mestizaje de papel. Dinámica demográfica y familias de calidad múltiple en Taximaroa (1667-1826). México: El Colegio de Michoacán, Universidad Autónoma de Coahuila, 2016.

Goody, Jack. La Familia Europea. España: Ed. Crítica, 2001. 
Gruzinski, Serge. El pensamiento mestizo. España: Ediciones Paidós Ibérica, 2000.

Gutiérrez Gutiérrez, José Antonio. “Aguascalientes a través del Padrón de 1648”. Folio, año 1, nº 1, 1999, 8-19.

Katzew, Ilona. La Pintura de castas. España: Ed. TURNER, 2004.

Kertzer, David I. - Barbagli, Mario (comps). La vida familiar a principios de la era moderna (1500-1789). Historia de la familia europea, vol. I. España: Paidós Ibérica, 2002.

Konetzke, Richard. "El mestizaje y su importancia en el desarrollo de la población durante la época colonial”. Revista de Indias, vol. VII (1946), 7-44 y 215-237.

Laslett, Peter. Family life an illicit love in earlier generations. Great Britain: Cambridge University Press, Reprinted with corrections, 1980.

López Beltrán, Carlos. "Sangre y temperamento. Pureza y mestizajes en las sociedades de castas americanas". En Sabores locales: Ensayos sobre historia de la ciencia en América latina, editado por Gorbach, Frida - López Beltrán, Carlos. México: El Colegio de Michoacán, 2008, 289-342.

Mateo, José. "Bastardos y concubinas. La Ilegitimidad conyugal y filial en la frontera pampeana bonaerense (Loboas 1810-1869)". Boletín del Instituto de Historia Argentina y Americana "Dr. Emilio Ravignani”, Tercera serie, no 13 (1996), 7-33.

McCaa, Robert, "Gustos de los padres, inclinaciones de los novios y reglas de una feria nupcial: Parral, 1770-1814”. Historia Mexicana, vol. 40, nº 4 (1991), 579-613.

Menéndez Valdés, José. "Noticias Corográficas de la Intendencia de Guadalajara adquiridas por el Dr. José Menéndez Valdéz en la visita que practicó en los años de 91 y 92", y “Censo general de la Intendencia (1791-1793)". En Descripción y Censo General de la Intendencia de Guadalajara, 1789-1793, estudio preliminar por: Serrera, Ramón Ma. México: Gobierno del Estado de Jalisco, 1980, 73-124 y 133-161.

Mintz, Sidney W. - Price, Richard, El origen de la cultura africano-americana. Una perspectiva antropológica. México: CIESAS, UAM, Universidad Iberoamericana, 2012.

Miño Grijalva, Manuel. El mundo novohispano. Población, ciudades y economía, siglos XVII y XVIII. México: Fideicomiso Historia de las Américas, Fondo de Cultura Económica, El Colegio de México, 2001.

Mörner, Magnus. La mezcla de razas en la historia de América Latina, Argentina: Ed Paidós, 1969.

- Estado, razas y cambio social en la Hispanoamérica colonial, México: SEP, Setentas 128, 1974.

Navarrete, Federico. Las relaciones interétnicas en México. México: Universidad Nacional Autónoma de México, 2004.

- México racista, una denuncia. México: Editorial Grijalbo, 2016.

Obara-Saeki, Tadashi - Viqueira Alban, Juan Pedro. El arte de contar tributarios. Provincia de Chiapas, 1560-1821. México: El Colegio de México, 2017.

Otis-Cour, Leah. Historia de la Pareja en la Edad Media. Placer y amor. España: Siglo XXI de España editores, 2000.

Paz, Octavio. El laberinto de la soledad. España: Fondo de Cultura Económica, 2a reimp, 1998.

Pollack, Aaron. "Hacia una historia social de tributos de indios y castas en Hispanoamérica. Notas en torno a su creación, desarrollo y abolición". Historia mexicana, vol. 66, $\mathrm{n}^{\mathrm{o}} 1$ (261), (2016), 65-160.

Rabell Romero, Cecilia Andrea. La población novohispana a la luz de los registros parroquiales (avances y perspectivas). México: Instituto de Investigaciones Sociales-Universidad Nacional Autónoma de México, 1990. 
Rodríguez Jiménez, Pablo, "Sangre y mestizaje en la América Hispánica”. Anuario Colombiano de Historia Social y de la Cultura, no 35 (2008), 279-309.

Rovira, José Carlos. "Para una revisión de la polémica mexicana dieciochesca con Manuel Martí, Deán de Alicante”. Sharq-Andalus, vol. 10-11 (1993-1994), 607-636.

Seed, Patricia. Amar, honrar y obedecer en el México colonial. Conflictos en torno a la elección matrimonial, 1574-1821. México: Alianza editorial, Consejo Nacional para Cultura y las Artes, 1991.

Serrera, José Ma . Guadalajara ganadera. Estudio regional novohispano, 1760-1805. Sevilla: Escuela de Estudios Hispanoamericanos, Consejo Superior de Investigaciones Científicas, 1977.

Sigüenza y Góngora, Carlos de. Seis Obras, Prólogo de Irving A. Leonard, Venezuela: Biblioteca Ayacucho, 1984.

Solórzano Pereira, Juan de. Política Indiana. España: impreso por Diego Díaz de la Carrera, 1648.

Stavenhagen Rodolfo. Sociología y subdesarrollo. México: Nuestro Tiempo, 1981.

Stolcke, Verena. Racismo y sexualidad en la Cuba colonial. España: Alianza editorial, 1992.

Tappan Velázquez, Martha Margarita. "La representación del mundo en el género de escritura del siglo XVI: Repertorio de los tiempos”. Tesis Doctoral, Universidad Autónoma Metropolitana, 2011.

Torres Franco, Carmen Paulina. ¿Entre parientes? Reconstrucción de familias y estrategias matrimoniales en la Parroquia de Encarnación, 1778-1822. México: El Colegio de Michoacán, 2017.

Tutino, John. Creando un nuevo mundo. Los orígenes del capitalismo en el Bajío y la Norteamérica española. México: El Colegio de Michoacán, Universidad Intercultural del estado de Hidalgo, Fondo de Cultura Económica, 2016.

Twinam, Ann. "Honor, sexualidad e ilegitimidad en la Hispanoamérica colonial". En Sexualidad y matrimonio en la América hispánica, siglos XVI-XVIII, coordinado por Lavrin, Asunción. México: Editorial Grijalbo, Consejo Nacional para la Cultura y las Artes, 1991, 127-171.

— "Las reformas sociales de los borbones: una reinterpretación revisionista", Revista Montalbán, $\mathrm{n}^{\mathrm{o}} 34$ (2001), 219-244.

- Vidas públicas, secretos privados. Género, honor, sexualidad e ilegitimidad en la Hispanoamérica colonial. Argentina: Fondo de Cultura Económica, 2009.

- Purchasing Whiteness. Pardos, Mulattos, and the Quest for Social Mobility in the Spanish Indies. EEUU: Stanford University Press, 2015.

Velázquez, María Elisa. Mujeres de origen africano en la capital novohispana, siglos XVII y XVIII. México: Instituto Nacional de Antropología e Historia, Universidad Nacional Autónoma de México, 2006.

— "Aportes y debates recientes sobre africanos y afrodescendientes en México". A Contra corriente. Una revista de historia social y literatura de América Latina, vol. 7, $\mathrm{n}^{\circ} 37.3$ (2010), 419-426.

Velázquez, María Elisa - Iturralde Nieto, Gabriela. Afrodescendientes en México, Una historia de silencio y discriminación. México: CONAPRED, INAH, 2012.

Villarroel, Hipólito. Enfermedades políticas que padece la capital de esta Nueva España. México: Editorial Porrúa, 1999.

Vinson III, Ben - Vaughn, Bobby. Afroméxico. Herramientas para la historia. México: Centro de Investigación y Docencia Económicas, Fondo de Cultura Económica, 2004. 
Viqueira Juan Pedro. "Reflexiones contra la noción histórica de mestizaje". Nexos, mayo 2010, 76-83.

Wiesner-Hanks, Merry. Cristiandad y sexualidad en la edad moderna. La regulación del deseo, la reforma de la práctica. España: Siglo XXI de España editores, 2000.

Wade, Peter. Race and Sex in Latin America. Great Britain: Pluto Press, 2009.

Zermeño-Padilla, Guillermo. "Del Mestizo al mestizaje: Arqueología de un concepto". $\mathrm{Me}$ moria y Sociedad, vol. 12, nº 24 (2008), 79-95. 